\title{
4 \\ Short Time-Interval Rainfall Disaggregation for Continuous Hydrologic Simulation
}

\section{Steven J. Burian and S. Rocky Durrans}

Traditionally design storms have been used to design and analyze urban drainage systems and hydraulic structures. Design storms can be developed with the desired temporal resolution to accommodate urban hydrology needs, but because the temporal distribution is generally arbitrary the application of complex disaggregation techniques is unwarranted. Continuous hydrologic simulation is recommended as an alternative to the traditional design storm approach for the design and analysis of hydrologic and hydraulic structures for reasons discussed in James (1994) and James and Robinson (1982). Continuous simulation models require long-term rainfall records (preferably more than 50 years) to generate the long-term statistical response of the hydrologic system required for accurate design and analysis of engineering systems and the evaluation of ecological and sustainability issues.

Accurate hydrologic simulation of small urban catchments requires the use of a rainfall time series with a fine temporal resolution. Studies have shown that when the response time of a watershed is shorter than the total duration of rainfall excess, the runoff rate is observed to depend on the depth of rainfall and the intensity distribution (Ball 1994; Woolhiser and Goodrich 1988; Hjelmfelt 1981). But for fully developed hydrographs Ball (1994) found the temporal pattern of rainfall excess to have little influence over the peak discharge. Thus, for short duration storms, coarse time resolution rainfall data may smooth the

Burian, S. and S. Durrans. 2002. "Short Time-Interval Rainfall Disaggregation for Continuous Hydrologic Simulation." Journal of Water Management Modeling R208-04. doi: 10.14796/JWMM.R208-04.

(C) CHI 2002 www.chijournal.org ISSN: 2292-6062 (Formerly in Best modeling practices for Urban Water Systems. ISBN: 0-9683681-6-6) 
high rainfall intensities (especially those observed during convective storms), and runoff could be underestimated. Hernandez and Nachabe (2000) demonstrated that when Hortonian runoff is dominant, infiltration and runoff are very sensitive to time resolution. They observed finer temporal resolution rainfall to produce more runoff than coarser rainfall. In general, hydraulic analysis of drainage systems requires rainfall data in 5-to 15 -minute increments to produce hydrographs that accurately predict peak flows (Nix 1994).

The procurement and management of long-term rainfall records is no longer a problem for locations where records are available electronically. Today, the primary difficulties with long-term rainfall records are (i) unavailability at the desired location or (ii) not being recorded at the desired temporal resolution. One solution to these problems would be to employ a synthetic rainfall generator to produce long-term rainfall fields with the desired spatial and temporal resolution. A second solution for circumstance (ii) (i.e. when a longterm rainfall record exists but has too coarse temporal resolution) is to employ a temporal disaggregation technique to disaggregate the record into a finer temporal resolution. The issue then becomes the selection and application of an appropriate disaggregation method to produce a long-term rainfall record at the desired temporal resolution.

This chapter compares several temporal rainfall disaggregation techniques applicable to continuous hydrologic simulation. The focus is the disaggregation of hourly rainfall records into sub-hourly increments, because in North America hourly rain gauges are relatively common and the records often have sufficient lengths for use in long-term continuous simulation. The rainfall disaggregation methods included in the study were selected based on the needs of hydrologic modelers. In general, hydrologic modelers desire techniques that are conceptually intuitive, easily grasped, and sufficiently flexible that they can be applied to any locality and for any desired level of disaggregation (so they can be relatively easily standardized). Based on these criteria, the five methods selected for comparison were the uniform distribution approach (described below), the quadratic spline and quadratic interpolating polynomial approaches (described by Durrans et al., 1999), the geometric similarity approach (the continuousdeterministic disaggregation model described by Ormsbee, 1989), and the backpropagation ANN approach (described by Burian et al., 2000). Methods that require the estimation of numerous parameters were not included in this study. The relative performance of the five techniques for disaggregating hourly rainfall records from Alabama into 15 -minute increments is reviewed in this chapter. Additional evaluation of the uniform distribution, the geometric similarity, and the ANN techniques is reported for 5-minute and 15-minute rainfall in Arkansas. 


\subsection{Literature Review}

The problem of inadequate temporal resolution of recorded and generated hydrological time series has persisted for several decades. Nearly 30 years ago Schaake et al. (1972) and Valencia and Schaake (1973) first introduced a disaggregation concept for generating hydrological time series with relatively fine temporal resolution. The technique integrated models for sequentially generating annual events with a disaggregation model for generating seasonal, monthly, weekly, or daily events within the year. Time series generated using this approach preserved both long-term and short-term variance and covariance properties, including seasonal variations, but did not address the intermittency associated with the daily rainfall process (Hershenhorn and Woolhiser, 1987). Mejia and Rousselle (1976) revised the Valencia-Schaake disaggregation model to include linkages with the past at different levels of aggregation. Disaggregation models similar to those of Valencia and Schaake and Mejia and Rousselle have been introduced by Salas et al. (1980) and Stedinger and Vogel (1984).

Numerous models have been introduced for synthetic generation of short time-interval rainfall depths. Pattison (1965) used a sixth-order Markov chain model to generate hourly rainfall values. Results indicated that the model adequately described the hourly rainfall process during storm events, but had problems accurately recreating the dry periods between storms. Srikanthan and McMahon (1983) developed models to stochastically generate sequences of hourly and six-minute interval rainfall depths. The hourly model satisfactorily preserved the means, standard deviations, and coefficients of skewness of hourly rainfall data for twelve rainfall stations in Australia. At ten of the twelve stations the daily rainfall statistics were also satisfactorily preserved. The sixminute model was able to reproduce most of the characteristics of the sixminute rainfall, but the number of parameters required is too large for practical application. Chan (1998) introduced a wavelet analysis technique applied to long-term short time-interval rainfall generation. The technique extracts the spectral behavior of an observed rain record at various temporal resolutions and uses a rain reconstruction method that combines stochastic modeling and time series analysis to produce a long-term rainfall record in 6-minute increments (James et al. 2000). The technique was demonstrated by generating a three-year rainfall record of 6-minute data. Results indicated that fairly good prediction of the general shape of a three-year rainfall record was obtained, but unacceptably high annual rainfall characteristics were produced.

Disaggregation models have been developed to distribute daily rainfall totals into individual storm events. For example, Hershenhorn and Woolhiser (1987) introduced a parameter-efficient stochastic approach to simulate the 
number of rainfall events in a day, and the amount, duration, and starting time of each event given the rainfall amount on that day and on the preceding and following days. The model produced storm event sequences that compared favorably with observed storm characteristics. The disaggregation model was also found to provide satisfactory predictions of disaggregated storm event characteristics at three other rainfall stations located within a $121-\mathrm{km}$ radius of the station used to develop the model.

Woolhiser and Osborn (1985) introduced a short time-interval model with their stochastic model for nondimensional thunderstorm rainfall at a point. The Woolhiser and Osborn (WO) model was evaluated using rainfall recorded at the Walnut Gulch Experimental Watershed in southeastern Arizona. Results indicated that the proposed model structure satisfactorily approximated summer thunderstorm rainfall. Woolhiser and Goodrich (1988) compared the WO short time-interval rainfall disaggregation model against two other rainfall disaggregation methods. The first comparison method estimated rainfall intensities during a storm event using an isosceles triangular distribution. The second comparison method assumed a constant (or uniform) intensity during the storm event. A runoff model simulated the runoff events produced by the observed rainfall event patterns and the disaggregated rainfall event patterns. For impervious catchments the WO model was shown to approximate the distribution of peak discharges more accurately than the isosceles and constant intensity distributions. For slow-responding catchments the differences between disaggregation methods disappeared, illustrating the point that if the response time of a catchment is longer than the total duration of rainfall excess, the peak discharge does not depend on the temporal rainfall intensity distribution (Hjelmfelt 1981).

Ormsbee (1989) presented two empirical disaggregation models for use in continuous hydrological simulation. The first, termed a discrete model, permits disaggregation of hourly values to three 20 -min values. The second, termed a continuous model, permits disaggregation of hourly rainfall into time intervals from 1 to $30 \mathrm{~min}$. Both models can be applied in either a deterministic or stochastic way, and both are based on the idea of making the disaggregated rainfall amounts for the central hour in a three-hour sequence geometrically similar (in the sense of a hyetograph) to the hourly amounts occurring in the three consecutive hours.

Durrans et al. (1999) introduced the application of quadratic splines to the disaggregation of hourly rainfall records into sub-hourly increments. The method is based on the idea of fitting a quadratic spline to representations of hourly rainfall data, and then employing the spline to interpolate rainfall amounts for sub-hourly time periods. The quadratic spline approach can incorporate sub-hourly rainfall variability, but the temporal distribution is constrained to fit 
the spline. Durrans et al. (1999) also introduced the application of quadratic interpolating polynomials to hourly rainfall disaggregation. The application is based on the idea of fitting a polynomial to hourly rainfall intensity data and then interpolating the sub-hourly intensities. Sub-hourly rainfall variability can be represented, but the method yields negative intensities for certain hourly rainfall patterns. A correction must be incorporated to eliminate the occurrence of negative intensities. This method operates efficiently on a long-term hourly rainfall record, without any storm type limitations.

Burian et al. (2000) presented two artificial neural network (ANN) applications for rainfall disaggregation. The first ANN model was a feedforward, three-layer neural net trained by backpropagation. The second ANN model was also a feed-forward, three-layer neural net, but it implemented a competitive learning algorithm based on a clustering process. Performance evaluations of the two ANN models showed that both models provided satisfactory predictions of the sub-hourly rainfall pattern and the peak storm event intensity, suggesting the need for further evaluation and improvement of the ANN techniques.

\subsection{Evaluation of Rainfall Disaggregation Techniques}

The first phase of the evaluation was performed for rainfall in the State of Alabama in the United States. The second phase further evaluated the top performing techniques for rainfall in the State of Arkansas. Four of the five disaggregation techniques have been described in detail elsewhere. The uniform distribution technique however requires a brief explanation. The uniform distribution method disaggregates hourly rainfall by assuming that the subhourly rainfall intensity distribution is constant. For example, if $40 \mathrm{~mm}$ of rainfall was measured for a single hour, disaggregation to 15-minute increments according to the uniform distribution would produce four $10-\mathrm{mm}$ pulses, one for each 15-minute increment in the hour. Applying a uniform distribution to sub-hourly rainfall is expected to produce unrealistic sub-hourly rainfall intensities for most storm events because the observed variability of sub-hourly rainfall cannot be accurately represented and peak intensities tend to be smoothed. It is known that the use of a uniform rainfall distribution leads to an under-prediction of peak discharges and in many cases runoff volumes and pollutant loads (James and Robinson 1982).

The evaluation involved aggregating sub-hourly rainfall records up to hourly intervals, then disaggregating the hourly record, and finally comparing the disaggregated sub-hourly rainfall patterns to the corresponding observed 
rainfall patterns. The performance of each technique was determined by comparing a subset of disaggregated storm events with the corresponding observed events. The performance was quantified by comparing several storm event statistics for the disaggregated pattern with the observed pattern and by calculating several measures of fit between the predicted rainfall pattern and the observed rainfall pattern.

The storm event statistics included in the comparison were the average peak intensity, the median peak intensity, and the coefficient of variation $\left(C_{v}\right)$ of the peak intensity. The peak intensity is the focus of the evaluation because of its importance for predicting peak discharges in hydrologic modeling. It should be noted that each of the methods evaluated in this study conserves rainfall volume at the hourly level, eliminating the need to evaluate performance in terms of the prediction of rainfall characteristics at higher levels of aggregation (hourly, storm event, daily, etc.). Two other performance measures were included in the analysis. The first, termed the signal to noise ( $S N)$ ratio, measures the fit between the predicted rainfall hyetograph and the observed hyetograph for the subset of evaluation storms. The $S N$ ratio is expressed as the ratio of the signal (represented by the known hyetograph) to the noise (represented by the error between the predicted and the known hyetographs):

$$
S N \text { ratio }=\frac{\sum_{i=1}^{N} p_{i}^{2}}{\sum_{i=1}^{N}\left(\hat{p}_{i}-p_{i}\right)^{2}}
$$

Here $\hat{p}_{i}$ and $p_{i}$ are the disaggregated and the known rainfall depth respectively, in each of the $\mathrm{N}$ pulses of a storm hyetograph. This statistic offers a measure of fit for the entire storm hyetograph. The $S N$ ratio describes the size of the signal (actual hyetograph) in comparison to the noise (prediction error). Higher values of the $S N$ ratio indicate a good prediction while small values $(<1)$ indicate that the magnitude of error is greater than the magnitude of the original hyetograph.

The second measure of fit is the relative error in predicting the peak subhourly intensity, which we termed $D_{\max }$ :

$$
D_{\max p}=\frac{\max \hat{p}_{i}-\max p_{i}}{\max p_{i}}
$$

Small values of $D_{\max }$ (in the absolute sense) indicate a good prediction. Positive values indicate a higher predicted maximum in the disaggregated hyetograph than in the known one, and negative values indicate the opposite. 


\subsection{Alabama Case Study}

Alabama is located in the Southeast United States and has an area of $81,850 \mathrm{~km}^{2}$. Physiographically Alabama can be divided into two main regions of approximately equal area: the southern extremities of the Appalachian Highlands in the north, and the coastal plain of the Gulf of Mexico in the south. Ground elevation ranges from sea level to a high of $733 \mathrm{~m}$, although much of the state lies below $200 \mathrm{~m}$ above sea level. The climate is temperate with a mean annual temperature of $16^{\circ} \mathrm{C}$ in the north and $19^{\circ} \mathrm{C}$ in the south. Precipitation is fairly evenly distributed throughout the year with most of the precipitation falling as rainfall. Mean annual rainfall is as high as $1650 \mathrm{~mm}$ near the Gulf Coast and as low as $1345 \mathrm{~mm}$ in the central parts of the state.

The evaluation used data recorded by a tipping bucket rain gauge located at the Warrior Lock and Dam in West Central Alabama (lat. 32:46, long. 87:49, el. $33.5 \mathrm{~m}$ ). The rainfall record spans from 1971 to 1994 , and has $97 \%$ coverage and a mean annual rainfall of $1295 \mathrm{~mm}$. The evaluation involved the selection of 196 storm events from the rainfall record. Storm events were separated by a single hour of zero recorded rainfall. Of the 196 storm events 98 were chosen for the evaluation storm set, while the other 98 were used in the training of the ANN model. Details of the ANN model training are reported in Burian et al. $(2000,2001)$. The training storms had a mean event depth of $24.6 \mathrm{~mm}$ and the evaluation storm set had a mean event depth of $27.2 \mathrm{~mm}$. The ANN model used in the Alabama evaluation contained three hidden neurons, was trained with 184 datasets for 1000 iterations, and had a learning rate of 0.5 and a momentum factor of 0.9 .

Table 4.1 compares the peak 15-minute intensity predictions for the 98 evaluation storm events selected from the Warrior Lock and Dam rainfall record. Overall the results indicate that each of the methods consistently underpredicts the peak 15 -minute intensity. The median $D_{\max p}$ ranged from -0.21 for the ANN approach to -0.50 for the uniform distribution technique. In terms of predicting the entire rainfall hyetograph, no trends were noticed. The $S N$ ratio for the quadratic spline, quadratic interpolating polynomial, uniform distribution, geometric similarity, and ANN were 1.76, 1.96, 2.0, 2.08, and 1.79, respectively. These results are somewhat expected because the prediction of the complete hyetograph is difficult at fine temporal resolutions. Overall, the Alabama rainfall evaluation suggested the $\mathrm{ANN}$ backpropagation approach and the continuous-deterministic geometric similarity technique provided the most accurate predictions of the peak rainfall intensity and the sub-hourly rainfall intensity distribution. Although the quadratic spline approach produced nearly the same accuracy as the geometric similarity technique it required more effort to implement. Therefore, the ANN and the geometric similarity technique were selected for further evaluation. 
Table 4.1 Comparison of rainfall disaggregation methods in terms of predicting the peak 15 -min intensity $\left(i_{p}\right.$ ) for the evaluation storm set (98 storm events) recorded at the Warrior Lock and Dam rain gauge.

\begin{tabular}{lcccccc}
\hline Statistic & Evaluation Storm Set & QS & QIP & UNI & GS & ANN \\
\hline Mean ip $(\mathrm{mm} / \mathrm{hr})$ & 31.8 & 21.0 & 17.4 & 13.9 & 20.3 & 24.6 \\
Median ip $(\mathrm{mm} / \mathrm{hr})$ & 20.3 & 14.6 & 13.7 & 10.2 & 15.8 & 18.0 \\
$\mathrm{C}_{\mathrm{v}}$ & 0.77 & 0.95 & 0.75 & 0.71 & 0.74 & 0.73 \\
Median $\mathrm{D}_{\max \mathrm{p}}$ & - & -0.36 & -0.45 & -0.5 & -0.34 & -0.21 \\
\hline $\mathrm{QS}=$ Quadratic spline, $\mathrm{QIP}=\mathrm{Quadratic}$ interpolating polynomial, UNI = Uniform distribution, \\
GS = geometric similarity, ANN = artificial neural network
\end{tabular}

\subsection{Arkansas Case Study}

The State of Arkansas is approximately $83,990 \mathrm{~km}^{2}$ and extends north-south $460 \mathrm{~km}$ and east-west $511 \mathrm{~km}$. Physiographically Arkansas can be divided into two main regions. A line drawn diagonally from the southwest corner to the northeast corner divides the forest-covered Ozark Plateau and Ouachita Mountains of the north and west from the fertile Gulf Coastal Plain and Mississippi River alluvial plain of the south and east. Elevation ranges from about $50 \mathrm{~m}$ above seas level to a high of $839 \mathrm{~m}$. The climate is temperate with a mean annual temperature of $14^{\circ} \mathrm{C}$ in the northwest and $19^{\circ} \mathrm{C}$ in the lowlands. Precipitation is well distributed throughout the year with slightly more in the spring months. Mean annual rainfall is as high as $1370 \mathrm{~mm}$ and as low as $1015 \mathrm{~mm}$. Snowfall is small, ranging from a mean annual low of less than 50 $\mathrm{mm}$ to a mean annual high of $400 \mathrm{~mm}$.

There were three objectives for the Arkansas evaluation. The first objective was to further evaluate the ANN backpropagation and the geometric similarity techniques for rainfall in a location other than Alabama. The second objective was to compare the performance of the techniques when disaggregating rainfall data with different recorded depth increments. We accomplished this objective by applying the techniques to 15 -minute rainfall recorded in 2.54 $\mathrm{mm}$ and $0.254 \mathrm{~mm}$ depth increments. The third objective was to evaluate the performance of the techniques for different temporal increments. We accomplished this objective by disaggregating Arkansas rainfall to 15 -minute increments and 5-minute increments.

Three tipping bucket rainfall-gauging stations were selected for this part of the evaluation. Two stations are located in Fayetteville, Arkansas (lat. 36:06 long. 94:10) and the third station is located in Eureka Springs, Arkansas (lat. 36:25 long. 93:47). The first station in Fayetteville is located at the agricultural experiment station and it reports 15-minute rainfall depths in $2.54 \mathrm{~mm}$ increments. The second station in Fayetteville is located on the Town Branch 
(TB) Creek and it reports 5 -minute rainfall depths in $0.254 \mathrm{~mm}$ increments. The Eureka Springs (ES) station reports 15 -minute rainfall depths in $0.254 \mathrm{~mm}$ increments. The Fayetteville Experiment Station (FES) has 93\% data coverage from 1971 to 1999 , the TB station has approximately $90 \%$ coverage from 1996 to 2000, and the ES station has $98 \%$ coverage from 1984 to 1999 .

The process of selecting training and evaluation storms from the Arkansas rainfall records began with the determination of the minimum interevent period that separates a rainfall record into individual storm events. The division of the rainfall record into discrete storm events is not necessary for the application of the disaggregation techniques, but it is necessary to select independent storm events for training the ANN and for the evaluation process. The interevent time definition (IETD) is the minimum interevent period between consecutive pulses of rainfall that isolates discrete storm events (Adams and Papa 2000). We performed three IETD estimation methods for the Arkansas rainfall records (see Adams and Papa (2000) for descriptions of the techniques): (i) autocorrelogram (plot of autocorrelation coefficient versus lag time), (ii) finding the IETD that produces a sample coefficient of variation for interevent times equal to one, and (iii) looking for the "bend-of-the-knee" in the plot of average annual number of storms versus IETD. The IETD determination methods were applied only to the FES rainfall record and the results were assumed to be similar for the TB and the ES stations since the stations are all in the same geographical area. The autocorrelogram indicated the IETD to be approximately 5-8 hours, while the plot of the average annual number of storms versus the IETD indicated an IETD of approximately 4-6 hours. The coefficient of variation method did not pinpoint an IETD. Overall, the analysis indicated the IETD to be approximately 7 hours.

For this study we were interested in disaggregating a five-year time series. During a given five-year period a wide variety of storm types will occur. Thus, a model must have the generalized prediction capability to predict a wide variety of storms. To ensure the ANN model would have generalized predictions we decided to select storm events for the training dataset that had a wide range of individual storm event characteristics, yet cumulatively had average storm event statistics (e.g. duration, intensity, depth, interevent period) similar to average statistics for the entire record. Initially, the FES, TB, and ES rainfall records were divided into independent storm events using an IETD of 7 hours. We then screened out storm events from the records that were unlikely to produce runoff, which were defined as storms producing less than $5.08 \mathrm{~mm}$ of rain. After removing storms that were not expected to produce runoff, training storms were selected from the records following the constraints described above. Evaluation storm sets were selected arbitrarily to be continuous 5-yr periods for the FES and ES rainfall records, dating from the 1990 water 


\section{Short Time-Interval Rainfall Disaggregation for Continuous Simulation}

year to the 1995 water year. The TB rainfall record is much shorter in length and only the 2000 calendar year was selected for the evaluation. The storm event characteristics for the entire record, training storms, and evaluation storms for the FES, ES, and TB records are shown in Tables 4.2, 4.3, and 4.4, respectively. The finalized Arkansas ANN rainfall disaggregation model contained four hidden neurons, was trained using 1000 training iterations with a learning rate of 0.5 and a momentum factor of 0.9 , and used data standardization limits of zero and 0.8 .

Table 4.2 Storm event characteristics for Fayetteville Experiment Station rain gauge.

\begin{tabular}{lrrr}
\hline & $\begin{array}{c}\text { Entire } \\
\text { Record }\end{array}$ & $\begin{array}{c}\text { Training } \\
\text { Storms }\end{array}$ & $\begin{array}{c}\text { Evaluation } \\
\text { Storms }\end{array}$ \\
\hline Number of Storms & 1158 & 195 & 219 \\
Mean Storm Depth (mm) & 23.5 & 22.0 & 24.1 \\
Median Storm Depth (mm) & 17.8 & 15.2 & 20.3 \\
Storm Depth C & 0.83 & 0.73 & 0.76 \\
Mean Storm Duration (hr) & 7.1 & 7.3 & 7.2 \\
Median Storm Duration (hr) & 5.0 & 6.0 & 5.0 \\
Storm Duration C & 0.81 & 0.82 & 0.78 \\
Mean Average Storm Intensity $(\mathrm{mm} / \mathrm{hr})$ & 5.2 & 5.0 & 5.0 \\
Median Average Storm Intensity $(\mathrm{mm} / \mathrm{hr})$ & 3.6 & 3.3 & 3.3 \\
Average Storm Intensity C & 1.40 & 1.02 & 1.06 \\
Average Peak Hour Intensity $(\mathrm{mm} / \mathrm{hr})$ & 10.2 & 9.9 & 9.8 \\
Median Peak Hour Intensity $(\mathrm{mm} / \mathrm{hr})$ & 7.6 & 7.6 & 7.6 \\
Peak Hour Intensity C & 0.94 & 0.80 & 0.80 \\
Average Interevent Period $(\mathrm{hr})$ & 110.0 & 109.6 & 100.9 \\
Median Interevent Period $(\mathrm{hr})$ & 62.0 & 60.0 & 57.0 \\
Interevent Period C & 1.36 & 1.23 & 1.31 \\
\hline
\end{tabular}

Table 4.3 Storm event characteristics for the Eureka Springs rain gauge.

\begin{tabular}{lccc} 
& Entire & Training & Evaluation \\
& Record & Storms & Storms \\
\hline Number of Storms & 753 & 227 & 247 \\
Mean Storm Depth (mm) & 23.5 & 25.3 & 23.4 \\
Median Storm Depth (mm) & 17.8 & 16.8 & 18.3 \\
Storm Depth Cv & 0.88 & 0.98 & 0.85 \\
Mean Storm Duration (hr) & 9.5 & 11.2 & 9.7 \\
Median Storm Duration (hr) & 7.0 & 9.0 & 7.0 \\
Storm Duration C & 0.86 & 0.88 & 0.82 \\
Mean Average Storm Intensity (mm/hr) & 4.3 & 4.6 & 3.8 \\
Median Average Storm Intensity (mm/hr) & 2.5 & 2.0 & 2.5 \\
Average Storm Intensity C & 1.85 & 2.2 & 1.4 \\
Average Peak Hour Intensity (mm/hr) & 9.5 & 9.6 & 9.6 \\
Median Peak Hour Intensity (mm/hr) & 7.1 & 6.6 & 6.9 \\
Peak Hour Intensity C & 1.0 & 1.14 & 0.87 \\
Average Interevent Period $(\mathrm{hr})$ & 98.7 & 100.8 & 90.7 \\
Median Interevent Period $(\mathrm{hr})$ & 54.0 & 57.0 & 52.0 \\
Interevent Period C & 1.17 & 1.12 & 1.10 \\
\hline
\end{tabular}


Table 4.4 Storm event characteristics for the Town Branch rain gauge.

\begin{tabular}{|c|c|c|c|}
\hline & $\begin{array}{l}\text { Entire } \\
\text { Record }\end{array}$ & $\begin{array}{c}\text { Training } \\
\text { Storms }\end{array}$ & $\begin{array}{c}\text { Evaluation } \\
\text { Storms }\end{array}$ \\
\hline Number of Storms & 181 & 140 & 41 \\
\hline Mean Storm Depth (mm) & 23.8 & 23.4 & 25.1 \\
\hline Median Storm Depth (mm) & 17.5 & 16.5 & 22.1 \\
\hline Storm Depth $\mathrm{C}_{\mathrm{v}}$ & 0.92 & 0.97 & 0.75 \\
\hline Mean Storm Duration (hr) & 13.3 & 14.4 & 9.6 \\
\hline Median Storm Duration (hr) & 9.0 & 10.0 & 7.0 \\
\hline Storm Duration $\mathrm{C}_{\mathrm{v}}$ & 1.01 & 1.00 & 0.94 \\
\hline Mean Average Storm Intensity ( $\mathrm{mm} / \mathrm{hr}$ ) & 2.9 & 2.8 & 3.5 \\
\hline Median Average Storm Intensity $(\mathrm{mm} / \mathrm{hr}$ ) & 1.8 & 1.5 & 2.5 \\
\hline Average Storm Intensity $C_{v}$ & 1.10 & 1.11 & 1.04 \\
\hline Average Peak Hour Intensity $(\mathrm{mm} / \mathrm{hr})$ & 9.2 & 8.6 & 11.2 \\
\hline Median Peak Hour Intensity $(\mathrm{mm} / \mathrm{hr})$ & 6.6 & 6.0 & 11.2 \\
\hline Peak Hour Intensity $\mathrm{C}_{\mathrm{v}}$ & 0.81 & 0.89 & 0.58 \\
\hline Average Interevent Period (hr) & 88.1 & 81.2 & 111.7 \\
\hline Median Interevent Period (hr) & 41.0 & 36.0 & 48.0 \\
\hline Interevent Period $C_{v}$ & 1.54 & 1.42 & 1.70 \\
\hline
\end{tabular}

\subsubsection{Results for 15-Minute Rainfall}

The results for the Arkansas 15-minute rainfall analysis are shown in Table 4.5 for the FES rainfall record and in Table 4.6 for the ES rainfall record. The results shown in Table 4.5 suggest the ANN and geometric similarity techniques provide relatively equal performance, well above the level achieved by the uniform technique. Comparing the $\mathrm{ANN}$ and the geometric similarity technique more closely, the ANN technique exhibits slightly improved peak intensity predictions. The performance of the uniform technique for the FES rainfall record was similar to its performance for the Warrior Lock and Dam record in Alabama (e.g. median $D_{\max }=-0.50$ ). On the other hand, both the ANN and the geometric similarity techniques predicted the peak intensity for the FES rainfall record with less accuracy than they did for the Alabama rainfall.

Table 4.5 Comparison of rainfall disaggregation methods in terms of predicting the peak 15 -min intensity $\left(i_{p}\right)$ for the evaluation storm set (219 storm events) recorded at the Fayetteville Experiments Station rain gauge.

\begin{tabular}{lcccc}
\hline Statistic & $\begin{array}{c}\text { Evaluation } \\
\text { Storm Set }\end{array}$ & Uniform & $\begin{array}{c}\text { Geometric } \\
\text { Similarity }\end{array}$ & ANN \\
\hline Mean ip $(\mathrm{mm} / \mathrm{hr})$ & 24.3 & 10.2 & 15.1 & 16.7 \\
Median $\mathrm{i}_{\mathrm{p}}(\mathrm{mm} / \mathrm{hr})$ & 20.3 & 7.6 & 12.0 & 10.7 \\
$\mathrm{C}_{\mathrm{v}}$ & 0.88 & 0.75 & 0.76 & 0.94 \\
Median $\mathrm{D}_{\max }$ & --- & -0.50 & -0.38 & -0.36 \\
\hline
\end{tabular}


Table 4.6 Comparison of rainfall disaggregation methods in terms of predicting the peak 15 -min intensity $\left(i_{p}\right)$ for the evaluation storm set $(247$ storm events) recorded at the Eureka Springs rain gauge.

\begin{tabular}{lcccr}
\hline Statistic & $\begin{array}{c}\text { Evaluation } \\
\text { Storm Set }\end{array}$ & Uniform & $\begin{array}{c}\text { Geometric } \\
\text { Similarity }\end{array}$ & ANN \\
\hline Mean i $(\mathrm{mm} / \mathrm{hr})$ & 20.2 & 9.3 & 13.6 & 12.0 \\
Median $\mathrm{i}_{\mathrm{p}}(\mathrm{mm} / \mathrm{hr})$ & 14.2 & 7.0 & 9.7 & 8.3 \\
$\mathrm{C}_{\mathrm{v}}$ & 0.88 & 0.82 & 0.84 & 0.90 \\
Median $\mathrm{D}_{\max \mathrm{p}}$ & - & -0.48 & -0.25 & -0.34 \\
\hline
\end{tabular}

The results in Table 4.6 illustrate trends similar to those observed in Table 4.5. Both the ANN and the geometric similarity techniques predict the peak intensity with more accuracy than the uniform technique. However, a notable difference between the FES and the ES results is the improved performance of the geometric similarity technique, giving a clear advantage over the ANN technique. This observation is contrary to the results of the Alabama evaluation where the ANN technique exhibited superior performance by a similar margin. One potential explanation is the difference in rainfall depth increments. Although the temporal increments are 15-minutes for each record, the ES record is recorded in $0.254 \mathrm{~mm}$ depth increments compared to the Alabama rainfall and the FES records that are recorded in $2.54 \mathrm{~mm}$ depth increments. All other sources of error being equal, the smaller recording increments will likely produce a more accurate representation of the rainfall pattern. Potentially, the improved performance by the geometric similarity technique might be attributable to the finer depth increment resolution in the rainfall record. But, to verify this will require additional testing.

Table 4.7 shows the median signal-to-noise ratios for the FES and the ES rainfall records for each disaggregation technique. Considering each rainfall station separately the results are consistent. No method exhibits significantly improved performance over another. But, interestingly each technique shows significant improvement in predicting the overall hyetograph for the ES rainfall record compared to the FES record. This observation supports the assertion that the finer depth increment data recorded at the ES station compared to the FES station might translate to improved prediction accuracy by the disaggregation techniques evaluated.

Table 4.7 Comparison of median signal-to-noise ratios calculated for the uniform, geometric similarity, and neural network disaggregation techniques.

\begin{tabular}{lccc}
\hline Rainfall Station & Uniform & $\begin{array}{l}\text { Geometric } \\
\text { Similarity }\end{array}$ & ANN \\
\hline FES (219 storms) & 1.71 & 1.67 & 1.59 \\
ES (247 storms) & 2.98 & 3.92 & 3.13 \\
\hline
\end{tabular}




\subsubsection{Results for 5-Minute Rainfall}

The performance of the uniform, geometric similarity, and ANN approaches for disaggregating Arkansas rainfall to 5-minute increments is summarized in Table 4.8. Unlike previous work with 15 -minute rainfall increments, the results are not encouraging for the ANN and the geometric similarity techniques. All three techniques perform relatively poorly with the uniform technique off significantly (consistently more than $50 \%$ under-prediction). This significant source of under-prediction by the uniform method must be factored into hydrologic modeling studies that use hourly rainfall data and execute the runoff simulation at short time increments (e.g. 5-10 minutes). Of the three methods, the geometric similarity technique produces mean and median peak intensity predictions closest to those calculated from the record. Similar to the observation for the ES rainfall record, the geometric similarity technique predicts the peak intensity with more accuracy on a more consistent basis than the ANN technique. In terms of predicting the overall hyetograph, the median $\mathrm{SN}$ ratio values were $1.73,1.63$, and 1.61 for the uniform, geometric similarity, and the ANN procedures, respectively. The $S N$ ratios suggest that none of the techniques provides improved prediction of the overall hyetograph. The evaluation of the 5-minute Arkansas rainfall indicates that further work is needed to improve the performance of the ANN for disaggregating hourly rainfall to 5-minute increments.

Table 4.8 Comparison of rainfall disaggregation methods in terms of predicting the peak 5-min intensity $\left(i_{p}\right)$ for the evaluation storm set (41 storm events) recorded at the Town Branch rain gauge.

\begin{tabular}{lcccc}
\hline Statistic & $\begin{array}{c}\text { Evaluation } \\
\text { Storm Set }\end{array}$ & Uniform & $\begin{array}{c}\text { Geometric } \\
\text { Similarity }\end{array}$ & ANN \\
\hline Mean ip $(\mathrm{mm} / \mathrm{hr})$ & 42.7 & 11.2 & 18.0 & 14.3 \\
Median ip $(\mathrm{mm} / \mathrm{hr})$ & 42.7 & 10.7 & 15.7 & 13.4 \\
C $_{\mathrm{v}}$ & 0.61 & 0.60 & 0.63 & 0.62 \\
Median $\mathrm{D}_{\max }$ & -0.72 & -0.54 & -0.64 \\
\hline
\end{tabular}

\subsection{Summary}

This chapter presents an evaluation of several temporal rainfall disaggregation techniques for use in continuous hydrologic simulation. A preliminary evaluation of five techniques applied to Alabama rainfall indicated that an ANN approach and a geometric similarity approach predicted the storm event peak intensity and the overall hyetograph with the most accuracy on the most 


\section{Short Time-Interval Rainfall Disaggregation for Continuous Simulation}

consistent basis. Further evaluation of the ANN and the geometric similarity techniques was conducted for rainfall in Arkansas. Results comparing the ANN and the geometric similarity techniques with the uniform distribution technique indicated that the ANN and the geometric similarity technique provided more accurate predictions of the peak intensity, consistent with the observations from the Alabama evaluation. Contrary to the results observed for the Alabama rainfall, the geometric similarity technique predicted the peak intensity of Arkansas 15-minute and 5-minute rainfall with more accuracy than the ANN technique. For the Eureka Springs 15-minute rainfall record the geometric similarity technique had a median $D_{\max }$ of -0.25 , while the ANN approach had a median $D_{\max p}$ of -0.34 . For the Town Branch 5-minute rainfall record the geometric similarity technique had a median $D_{\max p}$ of -0.54 , while the ANN approach had a median $D_{\max }$ of -0.64 .

It should be noted that the Arkansas evaluation involved the automated application of the ANN approach. For the Alabama study, significant judgment was used to select and standardize the training datasets, but for the Arkansas rainfall, computer codes were written to automate the selection of training storms and the formatting of training datasets. The automation cannot yet incorporate the manual filtering and quality control of training datasets that was performed during the Alabama evaluation. It is expected that the addition of quality control in the automation will improve the accuracy of the neural network approach.

In conclusion, at this time the artificial neural network rainfall disaggregation model produced for the State of Alabama is recommended for application to Alabama rainfall. Outside the State of Alabama, the geometric similarity technique is to be recommended for disaggregating long-term hourly rainfall records into sub-hourly increments until proper quality control and judgment can be incorporated into the neural network training process and improved performance can be documented for locations other than in Alabama.

\section{References}

Adams, B.J. and Papa, F. (2000). Urban stormwater management planning with analytical and probabilistic models. John Wiley \& Sons, Inc., New York.

Ball, J.E. (1994). "The influence of storm temporal patterns on catchment response." Journal of Hydrology, 158: 285-303.

Burian, S.J., Durrans, S.R., Tomic, S., Pimmel, R.L., and Wai, C.N. (2000). "Rainfall disaggregation using artificial neural networks." Journal of Hydrologic Engineering, 5(3): 299-307.

Burian, S.J., Durrans, S.R., Nix, S.J., and Pitt, R.E. (2001). "Training artificial neural networks to perform rainfall disaggregation." Journal of Hydrologic Engineering, 6(1):43-51. 
Chan, A.M.-C. (1998). Towards the generation of long-term, fine time-resolution rainfall data using wavelet analysis. M.Sc. thesis, University of Guelph.

Durrans, S.R., Burian, S.J., Nix, S.J., Hajji, A., Pitt, R.E., Fan, C.-Y., and Field, R. (1999). "Polynomial-based disaggregation of hourly rainfall for continuous hydrologic simulation." Journal of the American Water Resources Association, 35(5): 12131221.

Hernandez, T. and Nachabe, M. (2000). "Infiltration-runoff for complex rainfall sequences." In: Water quantity and quality in urban areas, Proceedings of the American Water Resources Association Annual Water Resources Conference, November 6-9, 2000, Miami, FL, pp. 263-266.

Hershenhorn, J. and Woolhiser, D.A. (1987). "Disaggregation of daily rainfall." Journal of Hydrology, 95: 299-322.

Hjelmfelt, A.T. (1981). "Overland flow from time-distributed rainfall." Journal of the Hydraulics Division, 107(2): 227-238.

James, W. (1994). Rules for responsible modelling. CHI, Guelph, Ontario.

James, W. and Robinson, M.A. (1982). "Continuous modeling essential for detention design." In: Proceedings of the ASCE Conference on Stormwater Detention Facilities, Henniker, NH, 163-175.

James, W., James, W.R.C., and Chan, A.M.-C. (2000). “Analysis of spatially kinematic rain using a web group decision support system, and generation of long-term fine time-resolution rain, for urban water systems modeling." In: From Precipitation Measurements to Design and Forecasting Modelling, Preprints of papers presented at the Fifth International Workshop on Rainfall in Urban Areas, Pontresina, Switzerland, 10-12 December 2000, 32-38.

Liou, E.Y.(1970). OPSET - Program for computerized selection of watershed parameter values of the Stanford Watershed Model. Research Report 34, University of Kentucky, Lexington, KY.

Mejia, J.M. and Rousselle, J. (1976). "Disaggregation models in hydrology revisited." Water Resources Research, 12(2): 185-186.

Nix, S.J. (1994). Urban stormwater modeling and simulation. Lewis Publishers, Boca Raton, FL., p. 133.

Ormsbee, L.E. (1989). "Rainfall disaggregation model for continuous hydrologic modeling." Journal of Hydraulic Engineering, 115(4): 507-525.

Pattison, A. (1965). "Synthesis of hourly rainfall data." Water Resources Research, 1(4):489-498.

Salas, J.D., Delleur, J.W., Yevjevich, V., and Lane, W.L.(1980). Applied modeling of hydrological series. Water Resources Publications, Littleton, Colorado.

Schaake, J.C., Ganslaw, M.J., Fothergill, J.W., and Harbaugh, T.E. (1972). "Multivariate rainfall generator for annual, seasonal, monthly, and daily events." In: Proceedings of the International Symposium on Mathematical Modelling Techniques in Water Resources Systems, Volume 2, Environment Canada, Ottawa, Canada, 437-460.

Srikanthan, R. and McMahon, T.A. (1983). "Sequential generation of short timeinterval rainfall data." Nordic Hydrology, 277-306.

Stedinger, J.R. and Vogel, R.M. (1984). "Disaggregation procedures for generating serially correlated flow vectors." Water Resources Research, 20(1): 47-56. 
56 Short Time-Interval Rainfall Disaggregation for Continuous Simulation

Valencia, R.D. and Schaake, J.C. (1973). "Disaggregation processes in stochastic hydrology." Water Resources Research, 9(3): 580-585.

Woolhiser, D.A. and Goodrich, D.C. (1988). "Effect of storm rainfall intensity patterns on surface runoff." Journal of Hydrology, 102: 335-354. 